\title{
Antibiotic treatment of exacerbations of COPD in general practice: long-term impact on health- related quality of life
}

This article was published in the following Dove Press journal:

International Journal of COPD

13 January 2010

Number of times this article has been viewed

\author{
Marc Miravitlles' \\ Carles Llor ${ }^{2}$ \\ Jesús Molina ${ }^{3}$ \\ Karlos Naberan ${ }^{4}$ \\ Josep M Cots ${ }^{5}$ \\ Fernando Ros ${ }^{6}$ \\ on behalf of the EVOCA \\ Study Group
}

'Fundació Clínic. Institut d'Investigacions Biomèdiques August $\mathrm{Pi}$ i Sunyer (IDIBAPS), Hospital Clínic, Ciber de Enfermedades Respiratorias (CIBERES), Barcelona, Spain; ${ }^{2}$ Primary Health Care Center 'Jaume I', Societat Catalana de Medicina Familiar i Comunitària, Universitat Rovira i Virgili, Tarragona, Spain; ${ }^{3}$ Primary Health Care Center 'Francia', Grupo de Respiratorio de la Sociedad Madrileña de Medicina Familiar y Comunitaria, Madrid, Spain; ${ }^{4}$ Primary Health Care Center 'Fuentes de Ebro', Grupo de Investigación del Instituto Aragonés Ciencias de la Salud (IACS), Zaragoza, Spain; ${ }^{5}$ Primary Health Care Center 'La Marina', Societat Catalana de Medicina Familiar i Comunitària, Facultat de Medicina, Barcelona, Spain; ${ }^{6}$ Medical Department, Bayer Healthcare, Barcelona, Spain
Correspondence: Marc Miravitlles Servicio de Neumologia, Hospital Clínic, Villarroel I70, E-08036 Barcelona, Spain Tel/Fax +34932275549

Emailmarcm@separ.es
Objective: To investigate the impact of exacerbations in health-related quality of life (HRQL) of patients with COPD and to compare the effect of treatment of COPD exacerbations with moxifloxacin (400 mg/day for 5 days) and amoxicillin/clavulanate (500/125 mg 3 times a day for 10 days) on HRQL.

Methods: 229 outpatients with stable COPD (mean age 68.2 years; mean FEV $\%$ predicted $49.3 \%$ ) participated in a prospective, observational study of 2 years' duration. The St George's Respiratory Questionnaire (SGRQ) was completed at baseline and every 6 months thereafter. Results: COPD exacerbations (mean 2.7 episodes/patient) occurred in 136 patients (124 patients received the study medications [amoxicillin/clavulanate 54, moxifloxacin 70]). Differences between baseline and the final visit were higher for moxifloxacin compared with amoxicillin/ clavulanate for total SGRQ score $(-2.60[13.1]$ vs 4.21 [16.2], $P=0.05)$ and "Symptoms" subscale ( -5.64 [16.7] vs 8.27 [21], $P=0.02)$. The same findings were observed in patients with two or more exacerbations.

Conclusions: In COPD outpatients, treatment of exacerbations with moxifloxacin had a more favorable long-term effect on quality of life than amoxicillin/clavulanate.

Keywords: COPD, exacerbations, moxifloxacin, amoxicillin/clavulanate, quality of life, SGRQ

\section{Introduction}

Chronic obstructive pulmonary disease (COPD) affects a large number of subjects worldwide and is characterized by a progressively rising epidemiological, clinical and socio-economic impact. ${ }^{1,2}$ The objectives of treatment are to decrease the burden of the disease through relief of symptoms, improvement of exercise tolerance, and prevention and treatment of exacerbations. Patients with moderate to severe disease suffer an average of two episodes of acute exacerbation a year, leading to hospital admission in $10 \%$ of cases. ${ }^{3}$ Furthermore, an increased number of past exacerbations is one of the best predictors for the risk of future recurrent exacerbations and relapse after treatment. ${ }^{4,5}$

Infections are responsible for $75 \%$ of exacerbations of COPD. ${ }^{6}$ In Spain, empiric antibiotic treatment is prescribed in more than $90 \%$ of cases of respiratory exacerbation of COPD, although microbiological analysis of sputum is only undertaken in $5 \%$ of patients. ${ }^{3,7,8}$ Penicillins, cephalosporins and macrolides are the most widely used antibiotics to treat exacerbation of chronic bronchitis and COPD in Spain, followed by quinolones. ${ }^{3}$ Appropriate antibiotic treatment is crucial since bacteriologic eradication is associated with longer infection-free intervals. ${ }^{9}$ Moxifloxacin is a fourthgeneration fluoroquinolone that has been shown to be effective against respiratory 
pathogens, including atypicals and those resistant to most common antibiotics. ${ }^{10-12}$ Moxifloxacin has demonstrated better eradication ${ }^{13}$ and faster recovery of symptoms ${ }^{14-16}$ in exacerbations of chronic bronchitis and COPD compared with standard therapy, in particular, with macrolides. Therefore, some guidelines recommend the use of moxifloxacin as first-line therapy in bacterial exacerbations in patients with moderate to severe COPD and in patients with mild COPD with risk factors. ${ }^{17}$

Exacerbations of COPD cause an important and permanent impairment in the quality of life of these patients. ${ }^{18,19}$ Different studies using both generic and disease-specific instruments have shown that health-related quality of life (HRQoL) is impaired in patients with severe COPD. ${ }^{20-22}$ However, most of these studies have been carried out in patients controlled by specialists in the hospital setting. For this reason, it is important to assess the effect of exacerbations on HRQoL of patients with less severe COPD visited in the primary care setting, where most COPD patients are attended.

The current study attempts to evaluate the impact of exacerbations on HRQoL and to investigate the effect of two antimicrobial treatments in modulating the impairment caused by exacerbations on the long-term evolution of health status. The study design and the impact of exacerbations on the whole population have been reported elsewhere..$^{23,24}$ The present article describes the effects of treatment of acute exacerbations with moxifloxacin versus amoxicillin/ clavulanate on changes of the St. George's Respiratory Questionnaire (SGRQ). The assessment of changes of HRQoL in association with antibiotic treatment of exacerbations is a novel approach to explore the effectiveness of different antimicrobial regimens in patients with COPD.

\section{Materials and methods \\ Design}

The EVOCA study (Spanish acronym of EVOlución de la CAlidad de vida en pacientes con EPOC - Evolution of the quality of life in patients with COPD) was a prospective, observational, multicenter study of a cohort of patients with COPD followed in primary care over a 2 -year period. The primary objective of the study was to assess the impact of exacerbations of COPD on the patients' quality of life measured by the SGRQ and to determine whether there were differences between patients treated with moxifloxacin and those treated with amoxicillin/clavulanate. Due to the lack of previous studies, the magnitude of changes in the SGRQ scores over a period of 2 years in patients with moderate COPD in primary care was unknown at the time of designing the study. ${ }^{23,24}$ Based on data of the only study available, 78 patients with severe COPD followed for one year were sufficient to detect significant differences in the SGRQ scores between patients with a higher or lower number of acute exacerbations than the median value. ${ }^{21}$ Accordingly, a sample of 200 patients with COPD was considered adequate to observe any significant changes in quality of life related to the frequency of exacerbations over 2 years, considering losses of up to $20 \%$ and that the frequency of exacerbation in patients with moderate COPD visited in primary care could be lower than in the reference study. ${ }^{21}$ Approximately 30 family physicians working in different primary care centers throughout Spain were asked to recruit the first 10 patients who met the inclusion criteria by nonprobabilistic sampling of consecutive cases. Patient enrolment took place between November 2002 and July 2003. The study protocol was approved by the Spanish health authorities and all patients gave written informed consent.

\section{Study population}

Eligible patients were adults over 40 years of age, smokers or ex-smokers of at least 10 pack-years, with chronic bronchitis characterized by persistent cough and sputum production for 3 months per year for at least 2 consecutive years, and stable COPD. Establishing the diagnosis of COPD required the observation of a non-reversible airflow obstruction characterized on post-bronchodilator forced spirometry by a $\mathrm{FEV}_{1}<80 \%$ of the theoretical value and $\mathrm{FEV}_{1} / \mathrm{FVC}<70 \%$ in stable phase (Global Obstructive Lung Disease [GOLD] stage II or greater). ${ }^{25}$ Clinical stability was defined as the absence of symptoms of exacerbation in the 6 weeks prior to inclusion. Patients who received antibiotic or steroid treatment for exacerbation in the 2 months previous to inclusion in the study were excluded, as were patients who had never smoked or had smoked less than 10 pack-years and those with bronchial asthma, cystic fibrosis, bronchiectasis not associated with COPD, alpha-1-antitrypsin deficiency, neoplasia, pneumonia, life expectancy of less than 2 years due to a severe concomitant disease, illiterate or unable to complete the SGRQ.

\section{Procedures and data collection}

Medication for stable COPD was left to the discretion of the attending physician. Patients were visited at the time of inclusion in the study (baseline, visit 1) and at 6-month intervals thereafter (visits 2, 3, and 4) until completion of the 
2-year study period (final, visit 5). At baseline, after verifying that the patient met eligibility criteria, the following data were recorded: demographics, symptoms and the degree of dyspnea, respiratory risk factors, treatment in the stable phase and number and characteristics of the exacerbations in the previous year, as well as the treatment administered. Dyspnea was evaluated according to the Medical Research Council (MRC) $\operatorname{scale}^{26}(0=$ no dyspnea; $1=$ dyspnea on going up two flights or stairs; 2 = breathlessness on going up one flight of stairs; 3 = dyspnea when walking on a flat surface; $4=$ dyspnea at rest). A forced spirometry was performed unless the patient had undergone spirometry within the last 6 months. Forced spirometry was repeated at the end of the study (visit 5).

At baseline and at each scheduled follow-up visit, patients completed the Spanish validated version of the SGRQ. ${ }^{27}$ The SGRQ is a standardized self-administered airways disease-specific questionnaire that contains 50 items (covering 76 levels) divided into three subscales: "Symptoms" (8 items), including several respiratory symptoms, their frequency and severity; "Activity" (16 items), concerned with activities that cause or are limited by breathlessness; and "Impacts" (26 items), which covers a range of aspects concerned with social functioning and psychological disturbances resulting from airway disease. A score ranging from 0 (no impairment or perfect state of health) to 100 (maximum impairment or worst possible state of health) is obtained. A score change of 4 points or more was considered clinically relevant in the health status of the patient. ${ }^{28}$ The SGRQ was completed by patients under the supervision of the investigators and in accordance with instructions of the manual.

Data of the five scheduled visits were recorded during a stable phase of the disease, that is, at least after one month of the last exacerbation episode. Patients were instructed to go to their physician on presentation of an exacerbation episode during the 2 years of the study. Exacerbations were defined in terms of increased dyspnea, sputum production, and sputum purulence that required a change in the patient's regular treatment. ${ }^{29}$ In addition to bronchodilator and/or steroid treatment, if the patient was considered candidate to be treated with oral antibiotics at the judgment of the responsible physician, the preferably prescribed treatment was a 5-day course of oral moxifloxacin, $400 \mathrm{mg}$ once daily, or a 10-day course of amoxicillin/clavulanate, 500/125 mg 3 times a day. Data on the exacerbation episode was recorded, and patients were appointed to the primary care center for a visit 7 to 10 days after starting antibiotic treatment to assess the outcome of the episode.
The antibiotic regimen prescribed for the first exacerbation episode was maintained for all successive episodes throughout the study period.

At each scheduled visit, information about episodes of exacerbation treated by the patients themselves with antibiotics and/or oral corticosteroids was obtained. These episodes were recorded as unreported exacerbations.

\section{Statistical analysis}

A descriptive analysis of data was performed. Unpaired Student's $t$ test was used for comparison of independent data that followed a normal distribution. Non-normally distributed variables were compared by means of the Wilcoxon test. The Student's $t$ test for repeated measurements was used for paired data, if they followed a normal distribution. Otherwise, the Wilcoxon rank sum test was applied. The chi-square $\left(\chi^{2}\right)$ test was used for the comparison of categorical variables. Statistical significance was set at $P<0.05$. The analysis was performed using SAS software (SAS Institute, Cary, SC, USA) version 9.1 for Windows.

\section{Results}

A total of 27 family physicians participated in the study and recruited 236 patients with stable COPD. Seven of these patients, however, did not meet the selection criteria and were not enrolled. Therefore, the study population included 229 patients, 218 men and 11 women, with a mean (standard deviation, SD) age of 68.2 (10.2) years. Baseline characteristics and HRQoL data of the study population have been described in a previous study. ${ }^{22}$ During the follow-up period, 136 patients had at least one exacerbation and 124 (91.1\%) patients received the study medications (amoxicillin/ clavulanate, $\mathrm{n}=54$; moxifloxacin, $\mathrm{n}=70)$. Thirty-two $(59.2 \%)$ patients in the amoxicillin/clavulanate group and 46 (65.7\%) in the moxifloxacin group completed the study. The disposition of patients is shown in Table 1 .

The mean (SD) $\mathrm{FEV}_{1}$ was $49.3 \%$ (15.3\%) indicating moderate impairment of pulmonary function. COPD has been present for a mean of 11 ( 8.1 years). A total of $81.2 \%$ of patients presented other concomitant diseases especially hypertension, diabetes, chronic heart failure, and ischemic heart disease. Seventy-seven percent of patients had had acute exacerbation episodes in the previous year, with a mean of $1.6(1.2)$ episodes and $15 \%$ were admitted to the hospital. The mean total score of the SGRQ was 40.7 (20.3). As shown in Table 2, patients who completed the study and those who did not showed comparable results of lung function tests, although a higher percentage of current smokers was 
Table I Disposition of the study population

\begin{tabular}{|c|c|c|c|c|}
\hline & Total & Amoxicillin clavulanate & Moxifloxacin & No study medication \\
\hline Patients recruited & 236 & & & \\
\hline Inclusion criteria were not fulfilled & 7 & & & \\
\hline Patients enrolled & 229 & 54 & 70 & 105 \\
\hline \multicolumn{5}{|l|}{ Follow-up disposition } \\
\hline Change of residence & & 3 & 4 & 7 \\
\hline Voluntary withdrawal & & I & I & 2 \\
\hline Death (not related to study medication) & & 4 & 2 & 8 \\
\hline Failure to attend scheduled visits & & 14 & 17 & 30 \\
\hline Total & & 22 & 24 & 47 \\
\hline Completed the study & 136 & 32 & 46 & $58^{\mathrm{a}}$ \\
\hline
\end{tabular}

aNo exacerbation episodes, $n=46$; not treated with antibiotics, $n=8$; treated with other antimicrobials, $n=4$.

observed among those who discontinued the study, as well as higher values in total score and the "Activity" subscale and lower values in the "Symptoms" subscale of the SGRQ. On the other hand, there were no statistically significant differences in baseline parameters between moxifloxacin-treated and amoxicillin/clavulanate-treated patients, although those who did not complete the study scored higher in the total score, "Symptoms" and "Activity" subscales of the SGRQ (Table 3).

During the 2-year follow-up period a total of 386 exacerbations were recorded, of which 51 (13.2\%) were unreported to the investigators and detected only at scheduled visits. In the group treated with amoxicillin/clavulanate, 24 patients $(75 \%)$ had two or more exacerbations compared with $29(63 \%)$ in the moxifloxacin group $(P=0.21)$. The mean number of episodes was 2.9 (2.2) in the moxifloxacin group vs 3.2 (3.0) in the amoxixillin/clavulanate group $(P=0.42)$. The time between the first and the second exacerbation was 198.38 (116.35) days among moxifloxacin-treated patients and 181.62 (154.56) days among those treated with amoxicillin/clavulanate; the differences were not statistically significant $(P=0.36)$.

A comparison of changes in SGRQ and respiratory function tests for the two groups of antimicrobial therapy is shown in Table 4. The change in SGRQ; that is the differences between scores at baseline and at the end of follow-up were significantly higher in the moxifloxacin group compared with amoxicillin/clavulanate for total SGRQ (-2.6 [13.1] vs 4.2 [16.2], $P=0.05)$ and "Symptoms" subscale (-5.6 [16.7] vs 8.3 [21], $P=0.02$ ). On the other hand, statistically significant differences in favor of a higher effect on HRQoL for moxifloxacin compared with amoxicillin/clavulanate were also observed in the subsets of patients with two or more exacerbations for the total SGRQ (6.6 [17.5] vs -2.3 [15.1],
$P=0.03)$ and "Symptoms" subscale (8.3 [23] vs -8.0 [16.8], $P=0.02$ ) (Figure 1). No correlation was found between changes in lung function $\left(\mathrm{FEV}_{1}\right)$ and total SGRQ scores (data not shown).

Compliance with antibiotic treatment was recorded in $95.7 \%$ of cases. Both regimens showed a highly favorable tolerability profile with two patients treated with moxifloxacin and four patients treated with amoxicillin/clavulanate presenting mild gastrointestinal complaints.

\section{Discussion}

The present study carried out to compare the long-term effect of treatment of acute exacerbations with moxifloxacin versus amoxicillin/clavulanate on the HRQoL of outpatients with COPD controlled in primary care showed a significantly higher beneficial impact of moxifloxacin on total scores of the SGRQ and the "symptoms" subscale than the standard regimen of amoxicillin/clavulanate. This favorable outcome was also observed in the subset of patents who had at least two episodes of acute exacerbation of COPD during the 2 -year study period. The length of time between the first and second exacerbation was about 16 days longer for the moxifloxacin group than for the amoxicillin/clavulanate group, but the differences were not significant probably because of the small sample size of the study. Therefore, it is likely that a better eradication rate with moxifloxacin would translate into a prolonged time to the next exacerbation. This effect was demonstrated in 355 patients with new exacerbations during the follow-up period in the MOSAIC trial. ${ }^{16}$ The mean time to event was 14 days longer with moxifloxacin treatment than comparators (amoxicillin, clarithromycin or cefuroximeaxetil) and the difference was statistically significant.

These findings, together with a more advantageous dosage (400 mg orally once daily for 5 days), support the use of 
Table 2 Baseline characteristics of the study population

\begin{tabular}{|c|c|c|c|c|}
\hline & $\begin{array}{l}\text { All patients } \\
(n=229)\end{array}$ & $\begin{array}{l}\text { Completed } \\
\text { the study } \\
(n=136)\end{array}$ & $\begin{array}{l}\text { Did not complete } \\
\text { the study } \\
(\mathrm{n}=93)\end{array}$ & $P$ value \\
\hline Sex, males & $218(95.2)$ & $|3|(96.3)$ & $87(93.6)$ & 0.33 \\
\hline Age, years, mean (SD) & $68.2(10.2)$ & $70(9.7)$ & $66.4(10.4)$ & 0.47 \\
\hline Active smoker & $78(34.2)$ & $36(26.5)$ & $42(45.7)$ & $<0.01$ \\
\hline Pack-years & $50.8(28.3)$ & $54.8(30.9)$ & $44.9(22.8)$ & 0.02 \\
\hline Duration of COPD, years, mean (SD) & II.I (8.I) & II.7 (8.1) & I0.I (8.0) & 0.08 \\
\hline Comorbidity & $186(8 \mid .2)$ & $107(78.7)$ & $79(84.9)$ & 0.23 \\
\hline Chronic cough & $195(85.2)$ & $109(80.1)$ & $86(92.5)$ & 0.01 \\
\hline Expectoration & $180(78.6)$ & $104(76.5)$ & $76(81.7)$ & 0.34 \\
\hline \multicolumn{5}{|l|}{ Dyspnea, grade } \\
\hline 0 or 1 & II 4 (49.7) & $73(53.7)$ & $4 I(44.1)$ & 0.19 \\
\hline 2 & $68(29.7)$ & $39(28.7)$ & $29(31.2)$ & 0.68 \\
\hline 3 or 4 & $47(20.5)$ & $24(17.7)$ & $23(24.7)$ & 0.19 \\
\hline \multicolumn{5}{|l|}{ Pulmonary function tests } \\
\hline FVC, L & $2.75(0.82)$ & $2.76(0.77)$ & $2.72(0.90)$ & 0.65 \\
\hline FVC, \% predicted & $66.4(16.5)$ & $66.3(15.6)$ & $66.7(18.1)$ & 0.72 \\
\hline $\mathrm{FEV}_{1}, \mathrm{~L}$ & $1.52(0.55)$ & $1.51(0.52)$ & $1.53(0.60)$ & 0.91 \\
\hline $\mathrm{FEV}_{1}, \%$ predicted & $49.3(15.3)$ & $48.7(14.5)$ & $50.3(16.5)$ & 0.51 \\
\hline $\mathrm{FEV}_{1} / \mathrm{FVC}, \%$ & $54.8(10.6)$ & $54.4(10.8)$ & $55.4(10.3)$ & 0.52 \\
\hline GOLD stages: Stage II & $109(49.3)$ & $65(48.5)$ & $44(47.8)$ & 0.76 \\
\hline Stage III & $52(23.5)$ & $34(25.4)$ & $18(19.5)$ & 0.67 \\
\hline Stage IV & $60(27.1)$ & $35(26.1)$ & $25(27.1)$ & 0.81 \\
\hline Exacerbations in the previous year & $176(77.2)$ & $99(73.3)$ & $77(82.8)$ & 0.09 \\
\hline Hospital admissions previous year & $35(15.4)$ & $20(14.8)$ & $15(16.1)$ & 0.78 \\
\hline \multicolumn{5}{|l|}{ Treatment of COPD } \\
\hline Short-acting beta ${ }_{2}$ agonists & $100(43.7)$ & $62(45.6)$ & $38(40.9)$ & 0.48 \\
\hline Long-acting beta ${ }_{2}$ agonists & $122(53.3)$ & $73(53.7)$ & $49(52.7)$ & 0.88 \\
\hline Ipratropium bromide & $139(60.7)$ & $82(60.3)$ & $57(6 \mid .3)$ & 0.88 \\
\hline Inhaled steroids & $120(52.4)$ & $79(58.1)$ & $4 I(44 . I)$ & 0.04 \\
\hline Theophyllines & $37(16.2)$ & $22(16.2)$ & $15(16.1)$ & 0.99 \\
\hline Mucolytic agents & $15(6.6)$ & $6(4.4)$ & $9(9.7)$ & 0.11 \\
\hline \multicolumn{5}{|l|}{ SGRQ, mean (SD) } \\
\hline Total score & $40.7(20.3)$ & $39.6(18.5)$ & $48.7(20.9)$ & 0.03 \\
\hline Symptoms & $49.0(20.8)$ & $47.8(30.9)$ & $50.8(22.5)$ & $<0.01$ \\
\hline Impact & $31.8(21.8)$ & $31.2(20.5)$ & $32.5(23.7)$ & 0.23 \\
\hline Activity & $51.6(25.0)$ & $49.6(22.5)$ & $54.4(28.0)$ & $<0.01$ \\
\hline
\end{tabular}

Notes: Data expressed as number of patients and percentages in parentheses unless otherwise stated.

Abbreviations: COPD, chronic obstructive pulmonary disease; FEV , forced expiratory volume in I second; FVC, forced vital capacity; SGRQ, St. George's Respiratory Questionnaire.

moxifloxacin as first-line therapy in bacterial exacerbations in patients with COPD and risk factors for treatment failure. The rationale for the prevention of exacerbations with moxifloxacin derives from a combination of at least three different factors: a) an immunomodulatory effect of the drug $;{ }^{30} b$ ) the rapid and more complete eradications prevents epithelial damage and restores the local defence mechanisms of the bronchial mucosa; $;{ }^{31}$ and c) as a result of the better eradication, fewer viable pathogens remain in the bronchial tissue after antimicrobial treatment, requiring a longer time for the bacterial population to increase sufficiently to induce a new exacerbation. ${ }^{32,33}$ On the other hand, the complete 
Table 3 Baseline characteristics of the patients who completed the 2-year follow-up according to treatment group

\begin{tabular}{|c|c|c|c|}
\hline & $\begin{array}{l}\text { Amoxicillin/clavulanate } \\
(n=32)\end{array}$ & $\begin{array}{l}\text { Moxifloxacin } \\
(n=46)\end{array}$ & $P$ value \\
\hline Sex, males & $32(100)$ & $43(93.4)$ & 0.14 \\
\hline Age, years, mean (SD) & $66.3(10.2)$ & $70(9.1)$ & 0.17 \\
\hline Active smoker & $9(28.1)$ & $4(8.7)$ & 0.02 \\
\hline Pack-years & $56.8(27.3)$ & $52.6(35.9)$ & 0.18 \\
\hline Duration of COPD, years, mean (SD) & II.3 (9.8) & $13.6(7.6)$ & 0.06 \\
\hline Comorbidity & $29(90.6)$ & $34(73.9)$ & 0.06 \\
\hline Chronic cough & $24(75)$ & 34 (73.9) & 0.91 \\
\hline Expectoration & $23(71.9)$ & $32(69.6)$ & 0.82 \\
\hline \multicolumn{4}{|l|}{ Dyspnea, grade } \\
\hline 0 or 1 & $21(65.5)$ & $21(45.6)$ & 0.23 \\
\hline 2 & $7(21.8)$ & $19(41.3)$ & 0.07 \\
\hline 3 or 4 & $4(I I .4)$ & $6(13)$ & NA \\
\hline \multicolumn{4}{|l|}{ Pulmonary function tests } \\
\hline FVC, L & $2.68(0.68)$ & $2.6 I(0.77)$ & 0.53 \\
\hline FVC, \% predicted & $63.2(13.9)$ & $64.8(15.5)$ & 0.74 \\
\hline $\mathrm{FEV}_{1}, \mathrm{~L}$ & $1.53(0.51)$ & $|.4|(0.53)$ & 0.27 \\
\hline $\mathrm{FEV}_{1}, \%$ predicted & $48.3(14.6)$ & $47.7(15.6)$ & 0.83 \\
\hline $\mathrm{FEV}_{1} / \mathrm{FVC}, \%$ & $56.7(11.2)$ & $53.5(10.4)$ & 0.10 \\
\hline GOLD stages: Stage II & $16(50.0)$ & $21(45.6)$ & 0.70 \\
\hline Stage III & $5(15.7)$ & $12(26.1)$ & 0.27 \\
\hline Stage IV & $10(31.3)$ & $13(28.3)$ & 0.77 \\
\hline Exacerbations in the previous year & $25(78.1)$ & $37(80.4)$ & 0.80 \\
\hline Hospital admissions previous year & $6(18.8)$ & $8(17.4)$ & 0.91 \\
\hline \multicolumn{4}{|l|}{ Treatment of COPD } \\
\hline Short-acting beta ${ }_{2}$ agonists & II (34.4) & $21(45.7)$ & 0.32 \\
\hline Long-acting beta ${ }_{2}$ agonists & $20(62.5)$ & $31(67.4)$ & 0.65 \\
\hline Ipratropium bromide & $23(71.9)$ & $28(60.9)$ & 0.31 \\
\hline Inhaled steroids & $17(53.1)$ & $35(76.1)$ & 0.03 \\
\hline Theophyllines & $9(28.1)$ & $6(13)$ & 0.09 \\
\hline Mucolytic agents & $4(8.7)$ & $0(0)$ & 0.08 \\
\hline \multicolumn{4}{|l|}{ SGRQ, mean (SD) } \\
\hline Total score & $37(14.7)$ & $44.8(19.4)$ & 0.06 \\
\hline Symptoms & $44.9(18.2)$ & $52.9(17.7)$ & 0.10 \\
\hline Impact & $28.6(15.8)$ & 38.1 (22.1) & 0.06 \\
\hline Activity & $47.6(20.8)$ & $51.9(23.2)$ & 0.16 \\
\hline
\end{tabular}

Notes: Data expressed as number of patients and percentages in parentheses unless otherwise stated.

Abbreviations: NA, not applicable; COPD, chronic obstructive pulmonary disease; FEV, , forced expiratory volume in I second; FVC, forced vital capacity; SGRQ, St George's Respiratory Questionnaire.

eradication of bacteria present in the airways is important for the prevention of resistance development. ${ }^{18,34}$

Patients with COPD experience impairment in daily life activities $^{35}$ and, additionally, exacerbations may have a longterm effect on their HRQoL. ${ }^{20}$ Spencer and Jones ${ }^{19}$ showed that the effect of exacerbations on HRQoL may persist for months. However, the greatest improvement in SGRQ scores takes place during the first month after the episode. To avoid interference of the last exacerbation with the SGRQ scores, measurements were obtained at least one month after the last exacerbation and during periods of clinical stability. The observation that patients with frequent exacerbations have worse SGRQ scores than patients with infrequent exacerbations ${ }^{21}$ was also confirmed in our study. ${ }^{24}$ In this 
Table 4 Changes in the SGRQ and respiratory function test according to the antibiotic treatment prescribed and exacerbation episodes

\begin{tabular}{|c|c|c|c|c|c|c|}
\hline & \multicolumn{4}{|c|}{ SGRQ scores } & \multirow[t]{2}{*}{$\mathrm{FEV}_{1}, \mathrm{~mL}$} & \multirow[t]{2}{*}{ FEV, \% } \\
\hline & Total & Symptoms & Activity & Impacts & & \\
\hline \multicolumn{7}{|c|}{ Amoxicillin/clavulanate, $n=32$} \\
\hline Baseline & $37.0(14.7)$ & $44.1(18.2)$ & $47.5(20.8)$ & $29.5(15.1)$ & $\mathrm{I} .53(0.5)$ & $48.3(14.6)$ \\
\hline Final visit & $41.2(17.3)$ & $52.3(21.8)$ & $53.3(22.4)$ & $31.7(17)$ & $\mathrm{I} .56(0.6)$ & $51.4(17.9)$ \\
\hline Difference & $4.2(16.2)$ & $8.3(21)$ & $5.7(21.6)$ & 2.2 & $0.03(0.4)$ & $3.06(14.3)$ \\
\hline \multicolumn{7}{|c|}{ One exacerbation, $n=8$} \\
\hline Baseline & $41.8(15.4)$ & $50.6(19.4)$ & $51.1(19.1)$ & $33.5(18.2)$ & $1.75(0.4)$ & $54.9(11.2)$ \\
\hline Final visit & $38.8(14.1)$ & $55.6(15.9)$ & $45.9(22.8)$ & $29.2(13.5)$ & I.7I (0.5) & $54.3(15.5)$ \\
\hline Difference & $-3.0(9)$ & $5.0(14.8)$ & $-5.2(11.1)$ & $-4.3(15)$ & $-0.04(0.4)$ & $-0.6(11.1)$ \\
\hline \multicolumn{7}{|c|}{ Two or more exacerbations, $n=24$} \\
\hline Baseline & $35.4(14.5)$ & $43.0(17.8)$ & $46.4(21.6)$ & $28.1(14.1)$ & $\mathrm{I} .45(0.5)$ & $46.0(15.2)$ \\
\hline Final visit & $42.0(18.5)$ & $51.3(23.6)$ & $55.8(22.3)$ & $32.6(18.1)$ & I.52 (0.6) & $50.4(18.9)$ \\
\hline Difference & $6.6(17.5)$ & $8.3(23)$ & $9.4(23.4)$ & $4.5(19.3)$ & $0.07(0.5)$ & $4.4(15.3)$ \\
\hline \multicolumn{7}{|c|}{ Moxifloxacin, $n=46$} \\
\hline Baseline & $44.8(19.3)$ & $52.9(17.7)$ & $54.3(20.8)$ & $39.0(21.5)$ & $\mathrm{I} .4 \mathrm{I}(0.5)$ & $47.8(15.7)$ \\
\hline Final visit & $42.2(19.2)$ & $47.3(16.4)$ & $56.1(22)$ & $36.2(21.1)$ & $1.49(0.5)$ & $52.8(18.2)$ \\
\hline Difference & $-2.6(13.1)$ & $-5.6(16.7)$ & I.8 (I5.4) & $-2.8(16.9)$ & $0.08(0.37)$ & $5.0(17.8)$ \\
\hline \multicolumn{7}{|c|}{ One exacerbation, $n=17$} \\
\hline Baseline & $39.3(23.2)$ & $45.1(18.8)$ & $49.8(26.5)$ & $37.2(23.3)$ & $1.46(0.6)$ & $49.8(15.1)$ \\
\hline Final visit & $36.1(21.9)$ & $43.6(13.6)$ & $50.8(28.1)$ & $31.2(25)$ & $\mathrm{I} .6 \mathrm{I}(0.6)$ & $57.9(21.7)$ \\
\hline Difference & $-3.2(9.2)$ & $-1.5(16)$ & $1.0(\mid 5.2)$ & $-6.0(12.3)$ & $0.15(0.5)$ & $8.1(17.8)$ \\
\hline \multicolumn{7}{|c|}{ Two or more exacerbations, $n=29$} \\
\hline Baseline & $48.0(16.4)$ & $57.5(15.5)$ & $56.6(17.2)$ & $40.0(20.9)$ & $1.38(0.5)$ & $46.6(16.1)$ \\
\hline Final visit & $45.7(16.7)$ & $49.5(17.7)$ & $58.8(17.9)$ & $39.0(18.4)$ & $\mathrm{I} .42(0.4)$ & $49.8(15.5)$ \\
\hline Difference & $-2.3(15.1)$ & $-8.0(16.8)$ & $2.2(15.8)$ & $-1.00(19.1)$ & $0.04(0.3)$ & $3.2(8.9)$ \\
\hline
\end{tabular}

Abbreviations: $\mathrm{FEV}_{1}$, forced expiratory volume in I second; SGRQ, St George's Respiratory Questionnaire.

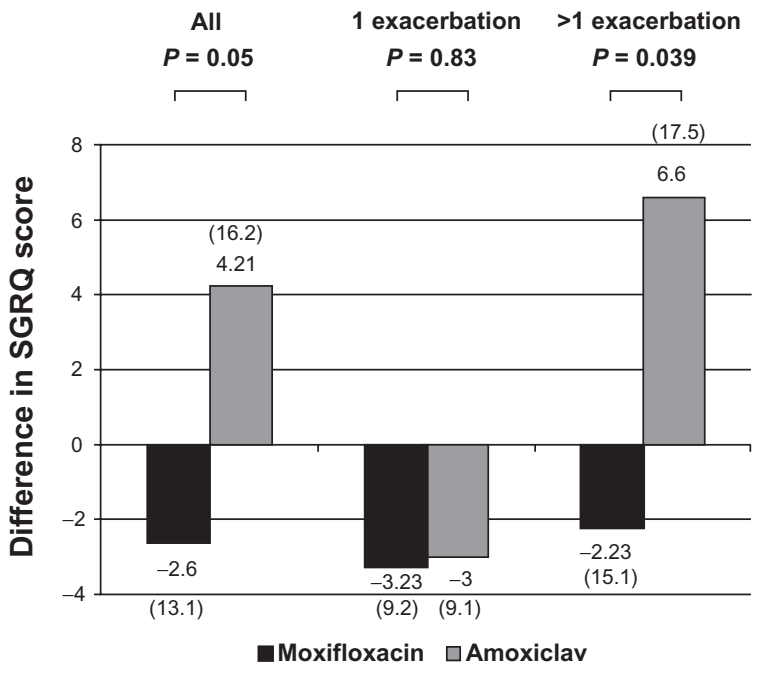

Figure I Differences in the total score of the St George's Respiratory Questionnaire (SGRQ) according to antibiotic treatment in the whole study population, in patients with one exacerbation of COPD and in those with more than one exacerbation. Standard deviation in parentheses. respect, the accumulation of episodes of acute exacerbation has an impact on the health status in the long term. ${ }^{19-21}$

The present results should be interpreted taking into account some limitations of the study, such as the relatively small number of patients treated with study medications that completed the study (46 in the moxifloxacin group and 32 in the amoxicillin/clavulanate group). Nonetheless, we observed significant differences in the impact of exacerbations on HRQoL according to the different antimicrobial treatment. These differences were increased in patients with frequent exacerbations. Those treated with moxifloxacin had a small nonclinically significant improvement of 2.24 units compared with an impairment of 6.60 units of patients with frequent exacerbations treated with amoxicillin/clavulanate, with this change being higher than the 4 units considered to be the clinically relevant change in the SGRQ. ${ }^{28}$ 
Although most demographics, clinical data, and results of respiratory function tests at baseline were similar for those who completed the study and received antibiotics than for those who did not complete the study, those lost during follow-up were less likely to be active smokers, complain of chronic cough and use inhaled corticosteroids, and also reported a lower tobacco consumption. Patients who withdrew from the study also scored higher in total score, "Symptoms" and "Activity" subscales of the SGRQ. This may indicate a higher impact of COPD on HRQoL in those patients who did no complete the 2-year study period. These differences should not influence the comparison between the impact of the two antibiotics on the changes in SGRQ scores over time. As far as we are aware, no previous study has been carried out to assess the long-term effect of two different antibiotic regimens for the treatment of exacerbation using HRQoL as the outcome measure. The effect of exacerbations on the HRQoL of patients with COPD has been demonstrated in previous studies ${ }^{18,20,21}$ but in none were the SGRQ scores used to determine the impact of treatment of COPD exacerbations with antimicrobials. In addition, the present study was performed in a nonclinical trial setting in ambulatory patients with COPD attended in primary care centers, which enhances the external validity of the study.

We conclude that in outpatients with moderate COPD controlled by primary care physicians during a 2 -year period, treatment of acute exacerbation episodes with a 5-day course of moxifloxacin (400 mg once daily) had a more favorable effect on health-related quality of life than the standard 10 -day course of amoxicillin/clavulanate $(500 / 125 \mathrm{mg}$ three times a day). Differences were observed between the two antibiotic regimens for both the total SGRQ score and the "Symptoms" domain. Health-related quality of life, particularly using disease-specific instruments such as SGRQ, should be included in the broad range of endpoints when assessing the long term outcome of exacerbation treatment of COPD.

\section{Acknowledgments}

Investigators participating in the EVOCA study: María Dolores Aicart Bort, Fernando Álvarez Guisasola, Carlos Brotons Cuixart, Eva Calvo Rosa, Isabel Castillo Ortíz, Ernesto Cerrada Cerrada, Juan Cimas Hernando, Ángel Collado Gil, Araceli Fernández Revuelta, Vicente A Corral Aliseda, Manuel Gómez García, Javier González Aliaga, Maite Lambán Sánchez, Armando Larnia Sánchez, Antonio José Madueño Caro, José Luis Martínez Carrasco, Ernesto Martínez Estrada, Jesús Molina París, Javier Muñoz
Guitiérrez, Karlos Naberan Toña, Isabel Pérez Cano, Javier Pérez Fernández, Concha Rodríguez Gallego, Elvira Rubio Benito, José Ignacio Sánchez González, Julia Sánchez Miró, and Santiago Valdearcos Enguidanos.

The authors thank Marta Pulido, MD, for editing the manuscript and editorial assistance.

\section{Ethical approval}

The study protocol was approved by the Spanish health authorities, according to the Spanish legislation for observational studies, and all patients gave written informed consent.

\section{Source of funding}

The EVOCA study has been sponsored by Bayer Healthcare, Barcelona, Spain. Bayer Healthcare contributed to the study design but it was not involved in data collection, data analysis, manuscript preparation and/or publication decisions.

\section{Disclosures}

The authors declare no conflicts of interest.

\section{References}

1. Chapman KR, Mannino DM, Soriano JB, et al. Epidemiology and costs of chronic obstructive pulmonary disease. Eur Respir J. 2006; 27:188-207.

2. Halpin DM, Miravitlles M. Chronic obstructive pulmonary disease: the disease and its burden to society. Proc Am Thorac Soc. 2006;3: 619-623.

3. Miravitlles M, Mayordomo C, Artés M, Sánchez-Agudo L, Nicolau F, Segú JL. Treatment of chronic obstructive pulmonary disease and its exacerbations in general practice. Respir Med. 1999;93:173-179.

4. Miravitlles M, Murio C, Guerrero T. Factors associated with relapse after ambulatory treatment of acute exacerbations of chronic bronchitis. Eur Respir J. 2001;17:928-933.

5. Miravitlles M, Guerrero T, Mayordomo C, Sánchez-Agudo L, Nicolau F, Segú JL. Factors associated with increased risk of exacerbation and hospital admission in a cohort of ambulatory COPD patients: a multiple logistic regression analysis. Respiration. 2000;67:495-501.

6. Papi A, Bellettato CM, Braccioni F, et al. Infections and airway inflammation in chronic obstructive pulmonary disease severe exacerbations. Am J Respir Crit Care Med. 2006;173:1114-1121.

7. Woodhead M, Gialdroni Grassi G, et al. Use of investigations in lower respiratory tract infection in the community: a European survey. Eur Respir J. 1996;9:1596-600.

8. Miravitlles M. Epidemiology of chronic obstructive pulmonary disease exacerbations. Clin Pulm Med. 2002;9:191-197.

9. Wilson R. Using antibiotics to delay exacerbations of chronic obstructive pulmonary disease. Hot Topics Respir Dis. 2006;2:21-28.

10. Miravitlles M. Moxifloxacin in the management of exacerbations of chronic bronchitis and COPD. Int J Chron Obstruct Pulmon Dis. 2007;2:191-204.

11. Wilson R, Kubin R, Ballin I, et al. Five day moxifloxacin therapy compared with 7 day clarithromycin therapy for the treatment of acute exacerbations of chronic bronchitis. J Antimicrob Chemother. 1999;44:501-513. 
12. Chodosh S, DeAbate CA, Haverstock D, Aneiro L, Church D. Short-course moxifloxacin therapy for treatment of acute bacterial exacerbations of chronic bronchitis. The Bronchitis Study Group. Respir Med. 2000;94:18-27.

13. Niederman MS, Anzueto A, Sethi S, et al. Eradication of $H$. influenzae in AECB: A pooled analysis of moxifloxacin phase III trials compared with macrolide agents. Respir Med. 2006;100:1781-1790.

14. Miravitlles M, Llor C, Naberan K, Cots JM, Molina J; for the EFEMAP study group. Variables associated with recovery from acute exacerbations of chronic bronchitis and chronic obstructive pulmonary disease. Respir Med. 2005;99:955-965.

15. Miravitlles M, Ros F, Cobos A, Kubin R, Tillotson G. The efficacy of moxifloxacin in acute exacerbations of chronic bronchitis: a Spanish physician and patient experience. Int J Clin Pract. 2001;5:437-441.

16. Wilson R, Allegra L, Huchon G, et al. Short-term and long-term outcomes of moxifloxacin compared to standard antibiotic treatment in acute exacerbations of chronic bronchitis. Chest. 2004;125:953-964.

17. Miravitlles M, Monsó E, Mensa J, et al. Antimicrobial Treatment of Exacerbation in Chronic Obstructive Pulmonary Disease: 2007 Consensus Statement. Arch Bronconeumol. 2008;44:100-108.

18. Doll H, Miravitlles M. Health-related QOL in acute exacerbations of chronic bronchitis and obstructive pulmonary disease. A review of the literature. Pharmacoeconomics. 2005;23:345-363.

19. Spencer S, Jones PW; for the GLOBE Study Group. Time course of recovery of health status following an infective exacerbation of chronic bronchitis. Thorax. 2003;58:589-593.

20. Miravitlles M, Ferrer M, Pont A, et al. Effect of exacerbations on quality of life in patients with chronic obstructive pulmonary disease: a 2 year follow up study. Thorax. 2004;59:387-395.

21. Seemungal TA, Donaldson GC, Paul EA, Bestall JC, Jeffries DJ, Wedzicha JA. Effect of exacerbation on quality of life in patients with chronic obstructive pulmonary disease. Am J Respir Crit Care Med. 1998;157:1418-1422.

22. Martin A, Rodriguez González-Moro JM, Izquierdo JL, et al. Healthrelated quality of life in outpatients with COPD in daily practice: the VICE Spanish study. Int J Chron Obst Pulmon Dis. 2008;3:683-692.

23. Miravitlles M, Molina J, Naberan K, Cots JM, Ros F, Llor C; in representation of the EVOCA study. Factors determining the quality of life of patients with COPD in primary care. Ther Adv Respir Dis. 2007;1:85-92.
24. Llor C, Molina J, Naberan K, Cots JM, Ros F, Miravitlles M; on behalf of the EVOCA study. Exacerbations worsen the quality of life of chronic obstructive pulmonary disease patients in primary care. Int J Clin Pract. 2008;62:585-592.

25. Rabe KF, Hurd S, Anzueto A, et al. Global strategy for the diagnosis, management, and prevention of chronic obstructive pulmonary disease: GOLD executive summary. Am J Respir Crit Care Med. 2007; 176:532-555.

26. Bestall JC, Paul EA, Garrod R, Garnham R, Jones PW, Wedzicha JA. Usefulness of the Medical Research Council (MRC) dyspnoea scale as a measure of disability in patients with chronic obstructive pulmonary disease. Thorax. 1999;54:581-586.

27. Ferrer M, Alonso J, Prieto L, et al. Validity and reliability of the St George's Respiratory Questionnaire after adaptation to a different language and culture: the Spanish example. Eur Respir J. 1996;9: 1160-1166.

28. Jones PW, Quirk FH, Bavestock CM, Littlejohns P. A self-complete measure of health status for chronic airflow limitation. The St George's Respiratory Questionnaire. Am Rev Resp Dis. 1992;145:1321-1327.

29. Cazzola M, MacNee W, Martinez FJ, et al. on behalf of the American Thoracic Society/European Respiratory Society task force on outcomes of COPD. Outcomes for COPD pharmacological trials: from lung function to biomarkers. Eur Respir J. 2008;31:416-468.

30. Dalhoff A, Shalit I. Immunomodulatory effects of quinolones. Lancet Infect Dis. 2003;3:359-371.

31. Sethi S, Murphy TF. Bacterial infection in chronic obstructive pulmonary disease in 2000: a state-of-the-art review. Clin Microbiol Rev. 2001; $14: 336-363$.

32. Chodosh S. Clinical significance of the infection-free interval in the management of acute bacterial exacerbations of chronic bronchitis. Chest. 2005;127:2231-2236.

33. Miravitlles M. Exacerbations of chronic obstructive pulmonary disease: when are bacteria important? Eur Respir J. 2002;20(Suppl 36) 9s-19s.

34. Stratton CW. Dead bugs don't mutate: susceptibility issues in the emergence of bacterial resistance. Emerg Infect Dis. 2003;9:10-16.

35. Alvarez-Gutiérrez FJ, Miravitlles M, Calle M, Gobartt E, López F, Martín A; EIME Study Group. Impact of chronic obstructive pulmonary disease on activities of daily living: Results of the EIME multicenter study. Arch Bronconeumol. 2007;43:64-72.
International Journal of COPD

\section{Publish your work in this journal}

The International Journal of COPD is an international, peer-reviewed journal of therapeutics and pharmacology focusing on concise rapid reporting of clinical studies and reviews in COPD. Special focus is given to the pathophysiological processes underlying the disease, intervention programs, patient focused education, and self management protocols.

\section{Dovepress}

This journal is indexed on PubMed Central, MedLine and CAS. The manuscript management system is completely online and includes a very quick and fair peer-review system, which is all easy to use. Visit http://www.dovepress.com/testimonials.php to read real quotes from published authors. 